\title{
An Improved Methodology for Massive Screening of Brachiaria spp. Genotypes for Resistance to Aeneolamia varia (Homoptera: Cercopidae)
}

\author{
CESAR CARDONA, JOHN W. MILES, AND GUILLERMO SOTELO ${ }^{1}$
}

\begin{abstract}
J. Econ. Entomol. 92(2): 490-496 (1999)
ABSTRACT Several species and genera of spittlebugs (Homoptera: Cercopidae) are economic pests of grasses in tropical America. They have the potential to cause serious losses on millions of hectares of improved pastures based on cultivars of several species of Brachiaria. Most of the available commercial cultivars of Brachiaria are susceptible to spittlebug. Resistance has been identified in several germplasm accessions and in one of the commercial cultivars, B. brizantha (A. Rich.) Stapf 'Marandú'. Brachiaria breeding projects require reliable techniques to screen for host plant resistance in large, segregating populations. A series of experiments was conducted to improve evaluation methodology. A smaller plant growth unit, supporting a single-stem, vegetative propagule, was developed and tested. Infestation levels for both adults ( 6 per plant) and for nymphs (10 per plant) were established. The refinements in screening methodology increase both reliability and capacity of the screen. Infestation of smaller plant propagules saves time, space, and physical resources. It also allows clear expression of insect damage symptoms and hence permits discrimination between tolerance and antibiosis in host plant reaction. Selection can be based on both resistance mechanisms. We outline a 2-yr Brachiaria breeding cycle which incorporates the new spittlebug resistance screening methodology.
\end{abstract}

KEY WORDS Aeneolamia varia, Brachiaria spp., resistance, mechanisms, antibiosis

A NUMBER OF grasses in the genus Brachiaria (Trin.) Griseb. have become important in tropical America as forages, particularly on infertile soils. The most widely grown are B. decumbens Stapf ('Basilisk'), B. humidicola (Rendle) Schweick ('Tully' and 'Llanero'), and B. brizantha (A. Rich.) Stapf ('Marandú') (Keller-Grein et al. 1996). Existing commercial cultivars are natural polyploid apomicts, thus each is a single genotype (Valle and Savidan 1996). With the exception of Marandú, commercial Brachiaria spp. genotypes are very susceptible to several spittlebug species comprising 8 genera (Ferrufino and Lapointe 1989, Lapointe et al. 1992). Aeneolamia varia (F.) is one of the most common species (Valério et al. 1996). Both nymphs and adults of this and other spittlebug species cause severe damage. As a result, the entire above-ground portion of the plant appears dry and dead. Dry matter production is reduced and forage quality is affected, thus reducing the productivity of damaged pastures (Valério et al. 1996). Although the economic impact of spittlebug damage has not been properly assessed, it is widely recognized that spittlebug susceptibility is among the most important constraints limiting the use of improved pastures in well-drained, acid soil savannas of tropical America (Lapointe et al. 1992, Miles and Valle 1996).

\footnotetext{
${ }^{1}$ Centro Internacional de Agricultura Tropical, CIAT, Apartado Aéreo 6713, Cali, Colombia.
}

Host plant resistance to spittlebug may be the only sustainable method of control for an insect that attacks grasses throughout millions of hectares. High levels of antibiosis resistance to A. varia have been detected in a number of Brachiaria accessions (Nilakhe 1987, Ferrufino and Lapointe 1989, Lapointe et al. 1989a). Brachiaria breeding programs were initiated in CIAT (Colombia) and EMBRAPA (Brazil) in the late 1980s. These were based on a sexual tetraploid developed in Belgium from the natural diploid sexual B. ruziziensis Germain \& Evrard. This sexual tetraploid biotype allowed genetic recombination between the closely related tetraploid apomictic species B. decumbens and $B$. brizantha (Swenne et al. 1981). The broad objective of the breeding projects is to combine the edaphic adaptation and quality characteristics of $B$. decumbens with the spittlebug resistance of $B$. brizantha Marandú in productive, high quality, apomictic genotypes (Lapointe and Miles 1992, Miles et al. 1995, Miles and do Valle 1996).

Because of the notoriously erratic spatial and temporal distribution of spittlebugs in naturally infested field plots (Ferrufino and Lapointe 1989), a bioassay designed to detect antibiosis, but not tolerance, was developed. This bioassay, based on artificial infestation of large plants grown in pots $(20.3 \mathrm{~cm}$ diameter $)$ in the glasshouse, was developed by Lapointe and collaborators (Ferrufino and Lapointe 1989, Lapointe et al. 1992). This assay involves establishing a constant number of nymphs per plant by infestation with eggs. 
Resistance (antibiosis) is assessed as percentage survival of nymphs to adult stage. This bioassay, referred to here as the traditional method, has the advantage over naturally infested field plots of greatly improved reliability and precision. With artificial mass rearing of the insect, evaluation of resistance is independent of environmental conditions in the field. However, the traditional method is costly, both in terms of physical resources (pots, soil, and glasshouse space) and in the technical manpower required to recover and count emerging adults over a period of nearly 1 mo. Because of the large size of the infested plants relative to the level of infestation, assessment of symptoms of plant damage from insect feeding is unreliable with this methodology.

The overall objective of the series of experiments reported here was to develop and evaluate a cheaper, quicker, and more reliable method of screening for resistance to spittlebug. In particular, we evaluated a much smaller plant growth unit, supporting a singlestemmed, rooted cutting rather than a multistemmed plant. We sought to determine optimum levels of infestation with both adults and nymphs which allow reliable discrimination between susceptible and resistant genotypes while being logistically feasible. To identify different mechanisms of host plant resistance to spittlebug in Brachiaria, we compared the reactions of a common set of host genotypes to artificial infestation with adults or with nymphs, as well as the effect of these same genotypes on nymphal survival. Further, we present data demonstrating the value of evaluating plant damage from nymphal feeding, an aspect that, in spite of its importance (Byers and Wells 1966, Hewitt 1989), has been neglected by other authors (Nilakhe 1987, Valério and Nakano 1992).

\section{Materials and Methods}

Plant Materials and Insects. Based on previous studies (Lapointe et al. 1992) germplasm accessions CIAT 0606 (B. decumbens Basilisk, susceptible), CIAT 0654 (common B. ruziziensis, susceptible) and CIAT 6294 (B. brizantha Marandú, resistant) were used as controls in screening trials. These genotypes were originally obtained from CIAT's Germplasm Unit. For all experiments reported here, vegetative propagation by cuttings was used to produce host plants. CIAT 0654 and CIAT 6294 also were used to determine optimum levels of infestation with adults and with nymphs. Thirty-six hybrid-derived clones of known reaction to spittlebug were used to compare the traditional (Ferrufino and Lapointe 1989) and the improved screening methods.

Aeneolamia varia was used in all experiments. Insects were mass-reared in a screenhouse following the methodology developed by Lapointe et al. (1989b). CIAT 0654 is the susceptible substrate on which the mass rearing facility is maintained. Newly emerged adults and mature eggs obtained by the methods described by Lapointe et al. (1989b) were used in the different experiments.

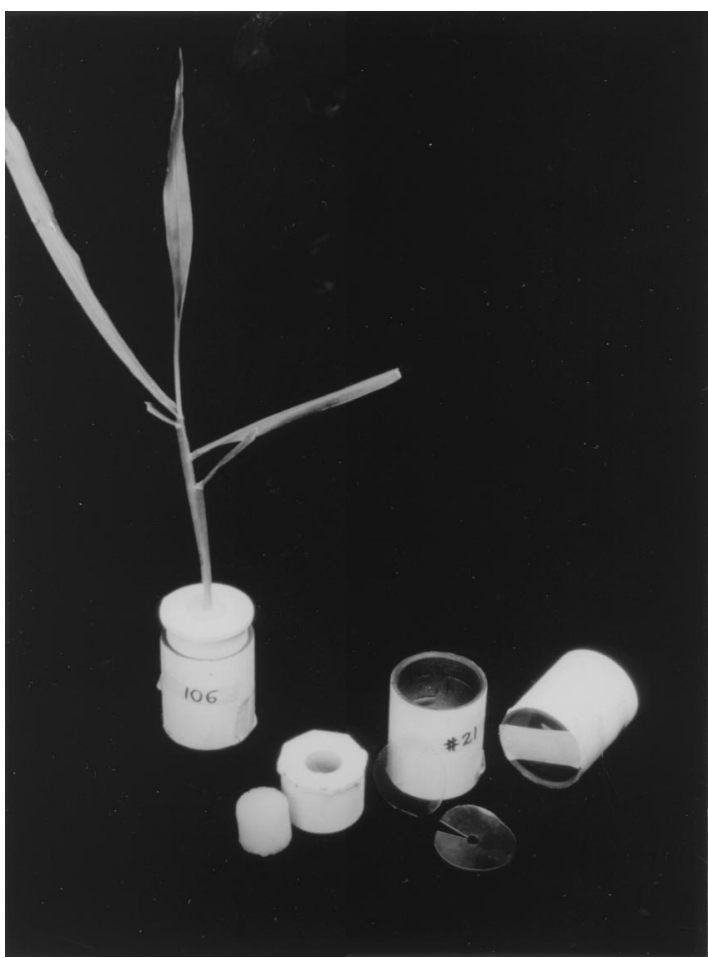

Fig. 1. Plant growth unit used for evaluation of Brachiaria genotypes for resistance to spittlebug.

Development of a New Plant Growth Unit for Resistance Evaluation. Several alternatives were compared. The one chosen can be called the single-tube technique. It consists of a PVC tube $(5.3 \mathrm{~cm}$ diameter, $6.5 \mathrm{~cm}$ long), open at both ends, and topped with a cap ( $4.8 \mathrm{~cm}$ diameter, $3.0 \mathrm{~cm}$ long) provided with a $2.5-\mathrm{cm}$ central hole through which a single plant stem is placed (Fig. 1). A plastic sheet (5.3 cm diameter) is taped to the lower, open end of the tube to hold soil while allowing excess water to drain. The tube is halffilled with $36 \mathrm{~g}$ of sterilized soil ( $\mathrm{pH} 4.8$ ) fertilized with the equivalent of $50 \mathrm{~kg} / \mathrm{h}$ a each of $\mathrm{N}, \mathrm{P}$, and $\mathrm{K}$. This soil forms a layer of $\approx 1.4 \mathrm{~cm}$ sustained by the plastic sheet. A single stem cutting is planted and held in place by means of a cylindrical piece of foam rubber inserted in the central opening in the cap. The cap and the foam rubber create a dark, humid environment at the base of the cutting that promotes rooting in the soil substrate. After initial rooting for $2 \mathrm{wk}$, the entire unit is inverted. With the tube inverted, the plastic sheet disk is removed from the bottom (now the top of the inverted tube), and the 1.4-cm layer of soil, permeated with roots, is pushed toward the top of the tube. The resulting space at the bottom of the tube is filled with soil $(\approx 40 \mathrm{~g})$ and the plastic sheet disk replaced. After growing upside down for $1 \mathrm{wk}$ to promote proliferation of superficial roots which will serve as feeding sites for nymphs, the units are returned to an upright position and arranged in shallow trays. They are grown for an additional week in a glasshouse at a mean temperature of $24.2^{\circ} \mathrm{C}$ (range, $19-27^{\circ} \mathrm{C}$ ) and mean relative 
humidity of $75 \%$ (range, $70-90 \%$ ). If propagation is successful, the single-stem rooted cuttings are ready for infestation 1 mo after planting.

Levels of Infestation.Adults. To determine optimum levels of infestation for resistance screening using the new plant growth unit, 30-d-old plants (a preliminary trial showed no difference in resistance expression between 15- and 30-d-old plants) of the resistant accession CIAT 6294 and the susceptible accession CIAT 0654 were each infested with $2,3,4,5,6,7,8,9$, or 12 newly emerged adults per plant. An uninfested control was included. For each level of infestation, 10 plants of each genotype were infested inside separate $60-\mathrm{cm}$, cubical, muslin-covered cages. Hence, the experimental unit was a single cage with one genotype-infestation level combination. The experiment was replicated 3 times in complete blocks in time. The genotype-infestation level treatment combinations were randomized among cages within blocks. Damage scores were recorded on an individual plant basis. The adults were allowed to feed for $10 \mathrm{~d}$ and then removed. The plants were immediately scored for damage symptoms by means of a $1-5$ visual scale ( 1 , no visible damage; $2,25 \%$ of foliar area affected; $3,50 \% ; 4,75 \%$; 5 , all foliar area affected and dry). The plants were cut at soil level, taken to a laboratory and dried in an oven at $40^{\circ} \mathrm{C}$. Dry weight of plants at each infestation level was then recorded and the data were used to calculate percentage dry weight losses with respect to corresponding uninfested controls.

Nymphs. To determine optimum levels of infestation with nymphs, 30-d-old plants of CIAT 6294 and CIAT 0654 were exposed to $2,3,5,7,10,12$, or 15 nymphs per plant. Uninfested controls were used for comparison. In a completely randomized design with 10 replications (single-plant experimental unit), each single-plant growing unit was infested with mature eggs of A. varia previously selected for viability by visual inspection and incubated in the laboratory (Lapointe et al. 1992). Eggs were checked $24 \mathrm{~h}$ after infestation and unhatched eggs were replaced. Most often, selection of eggs in the laboratory translates into $100 \%$ eclosion. Infestation was allowed to proceed without interference until all nymphs were fully mature or adult emergence first occurred. At this point, plants were scored for symptoms using the same scale as for adult damage. The experiment with nymph infestation was repeated.

Comparison of Screening Methodologies. To determine the reliability of the new screening technique to detect resistance and to characterize further the mechanisms underlying resistance to spittlebug, 39 genotypes were chosen. These included the germplasm accessions CIAT 0606, CIAT 0654, and CIAT 6294 plus 36 hybrid clones previously evaluated for reaction to spittlebug by the traditional methodology (Ferrufino and Lapointe 1989, Lapointe et al. 1992). The 39 genotypes were propagated to single-plant PVC growing units as previously described. Two sets of 10 plants each were propagated for each genotype. Two experiments were conducted. Each consisted of 10 replicates of single-plant experimental units in a completely randomized design. One experiment was infested with adults, the other with nymphs. To infest with adults, 390 (10 reps, 39 genotypes) 30-d-old plants were placed inside a muslin-covered cage $(2 \mathrm{~m}$ long, $0.8 \mathrm{~m}$ wide, $1 \mathrm{~m}$ tall). The level of infestation was 6 adults per plant. Adults were allowed to feed for $10 \mathrm{~d}$ and then removed. The plants were immediately scored for damage symptoms by means of the 1-5 visual scale previously described. Genotypes were arbitrarily classified as resistant, intermediate, or susceptible on the basis of mean score as follows: 1-2, resistant; 2.1-3.0, intermediate; $>3.0$, susceptible.

To evaluate resistance to nymphs, 30 -d-old plants were infested with 10 mature eggs previously selected and incubated in the laboratory (Ferrufino and Lapointe 1989). Eggs were checked 24 h after infestation, and unhatched eggs were replaced. Nymphal development was allowed to proceed without interference until full maturity or adult emergence first occurred. At this point, plants were scored for symptoms using the above mentioned scale and genotypes were classified as resistant, intermediate, or susceptible as explained previously. In addition, the number of live nymphs and/or adults present in each pot was recorded to calculate percentage nymph survival which was then used to classify the genotypes as resistant $(<30 \%$ survival), intermediate $(31-50 \%)$, and susceptible $(>50 \%)$. Resistance ratings for each genotype were compared with those obtained in previous years using the traditional screening methodology.

Statistical Analysis. All data were submitted to statistical analysis using SAS (SAS Institute 1988). Regressions of visual damage scores (means of 10 singleplant observations per experimental unit, 3 replicates) and percentage dry weight reduction ( 2 replicates only) on adult infestation levels were analyzed separately for each replicate and genotype. Data from the uninfested, control treatments were excluded from the regression analysis. Intercepts were compared and regression coefficients were tested for homogeneity. Similarly, regressions of visual damage scores on nymph infestation levels (single-plant experimental units, 10 replicates per experiment) were calculated for each of the genotypes in 2 experiments and then tested for homogeneity of intercepts and regression coefficients. In the trials aimed at comparing the traditional with the new screening methodologies, data were analyzed by 1-way analysis of variance (ANOVA). Descriptive statistics and simple linear correlation coefficients between response variables also were determined using SAS (SAS Institute 1988). When the $F$ test was significant, comparison of means was by the least significant difference (LSD) test $(P<0.01)$. Percentages were transformed to arcsine $\sqrt{\text { proportion. }}$. Untransformed means are presented.

\section{Results and Discussion}

Levels of Infestation with Adults and Nymphs. Analyses of the regression of mean damage scores on adult infestation levels for the 3 replications separately 


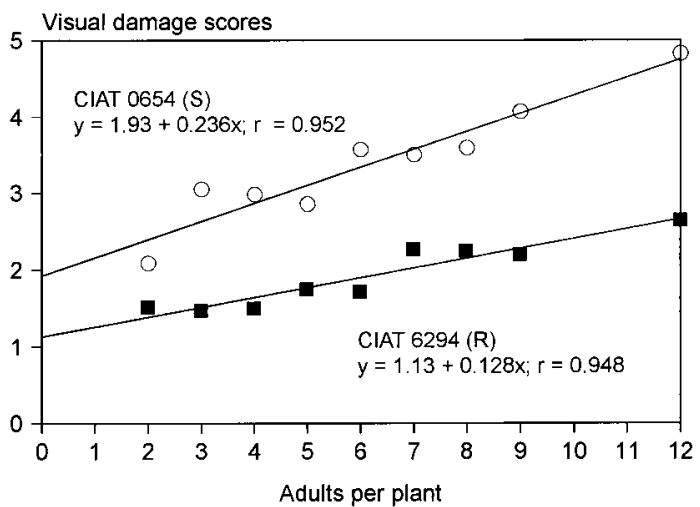

Fig. 2. Relationship between adult infestation levels and damage (assessed using a 1-5 visual scale) caused by A. varia on 2 Brachiaria spp. genotypes.

gave no evidence either of differences in intercepts or of nonhomogeneity of the 3 regression coefficient estimates for either the susceptible (CIAT 0654; $F=$ $0.92 ; \mathrm{df}=2,21$ ), or the resistant (CIAT 6294; $F=1.13$; $\mathrm{df}=2,21)$ genotype. Hence, data from the 3 replicates were pooled and a single regression (Fig. 2) was calculated for each genotype (using means over replicates). Susceptible and resistant genotypes differed in response to increasing levels of infestation $(t=2.62$, $\mathrm{df}=14(\alpha=0.05)$. As shown in Fig. 2, the relationship between adult infestation levels and visual damage scores for the susceptible genotype CIAT 0654 can be expressed as $\mathrm{y}=1.93+0.236 \mathrm{x}$, where $\mathrm{x}$ is the number of adults per plant ( $\mathrm{SE}$ of regression $=0.029 ; r=0.95$ ). According to this relationship, damage levels of 3.1 and 3.5 (susceptible reactions) are obtained with levels of infestation of 4.9 and 6.6 adults per plant, respectively. A level of infestation of 6 adults per plant was chosen for future routine screening.

We observed less damage on CIAT 6294 than on a susceptible host genotype (CIAT 0654) at a given level of adult infestation. Increasing the level of adult infestation produced a smaller reduction in host plant dry weight on CIAT 6294 than on CIAT $0654(t=14.3$, $\mathrm{df}=14, P<0.001$ ) (Fig. 3). The low level of adult damage on CIAT 6294 may be a reflection of either of 2 distinct mechanisms (or a combination of both), which are impossible to distinguish with the experimental procedure used in the current study. Tolerance to adult spittlebug of CIAT 6294 and a few other Brachiaria spp. genotypes, expressed as number of insect-days required to cause severe feeding damage in fully grown plants, was reported by Ferrufino and Lapointe (1989). However, a lower level of damage at a given level of infestation may be a result of reduced feeding rather than true tolerance. Lapointe et al. (1992) assessed adult feeding by measuring 24 -h production of excreta of adults confined in Parafilm sachets to plants of different Brachiaria genotypes. Their data show that excreta production (hence, feeding) was less on CIAT 6294 than on a susceptible (CIAT 0606) or on a tolerant host (CIAT 6133, B. humidicola

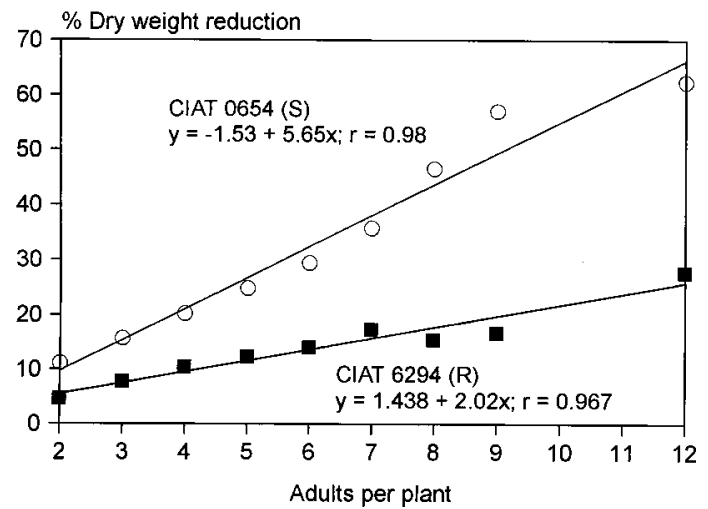

Fig. 3. Relationship between adult infestation levels and percentage dry weight reduction caused by A. varia on 2 Brachiaria spp. genotypes.

Llanero), a result that they suggest may be caused by a toxin or antifeedant in CIAT 6294. Hence, reduced feeding rather than true tolerance may explain the low level of adult damage symptoms and the lower rate of dry weight reduction with increasing infestation levels found here for CIAT 6294. Whatever the cause, our results confirm that this effect can be measured by means of a simple bioassay in only $10 \mathrm{~d}$. Visual damage scores proved to be efficient in predicting biomass losses as demonstrated by the close relationship between visual damage score and percentage dry weight reduction $(r=0.944, P<0.001)$.

Regressions of mean visual damage scores on nymph infestation levels for the susceptible genotype CIAT 0654 in 2 consecutive trials did not differ in terms of intercepts $(F=0.98$; $\mathrm{df}=1,18 ; P<0.01)$ or slopes $(t=0.12, \mathrm{df}=10, P<0.01)$. The single regression line calculated (Fig. 4) indicated that the relationship between nymph infestation levels and visual damage scores can be expressed as y $=2.10+$ $0.167 \mathrm{x}$, where $\mathrm{x}$ is the number of nymphs per plant (SE of regression $=0.009 ; r=0.992)$. According to this,

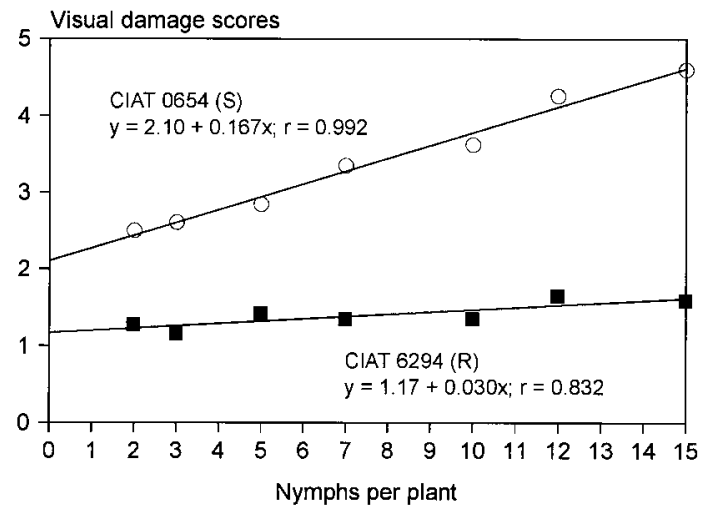

Fig. 4. Relationship between nymph infestation levels and damage (assessed using a 1-5 visual scale) caused by $A$. varia on 2 Brachiaria spp. genotypes. 
damage levels of 3.1 and 3.5 (susceptible reactions) are obtained with levels of infestation of 6 and 8.4 nymphs per plant, respectively. Fully susceptible reactions (4.0) would be obtained with 11.3 nymphs per plant. We decided to set the level of infestation for future screenings at 10 nymphs per plant. This facilitates handling of the material by technical support staff and calculations of percentage survival based on 10 nymphs per replication, 10 replications per genotype, in large-scale screenings for resistance. A single regression line also was calculated for the resistant genotype CIAT 6294. The relationship can be expressed as $\mathrm{y}=1.17+0.03 \mathrm{x}$ ( $\mathrm{SE}$ of regression $=0.009$; $r=0.832$ ). The minor damage shown by CIAT 6294 at high infestation levels is an expression of the antibiotic effect present in this genotype (Ferrufino and Lapointe 1989, Lapointe et al. 1992). Regression analysis showed that the 2 lines in Fig. 4 have significantly different slopes $(t=2.44, \mathrm{df}=10, P<0.05)$. This difference suggests that evaluation of genotypes for nymphal damage scores 30-35 d after infestation could be used to discard susceptible genotypes that lack antibiosis or tolerance to nymphal damage. The ones showing little damage would be checked for nymphal survival to ascertain that they do possess antibiosis. This ability to screen for both tolerance and antibiosis is an important advance in the massive screening of genotypes. Previous screening methodologies based selection on percentage survival of nymphs feeding on fully grown plants, which made evaluations of nymphal damage slow, difficult, and unreliable.

Comparison of Screening Methodologies. One-way ANOVA for the 39 genotypes used to compare screening methodologies revealed highly significant differences among genotypes tested for adult damage scores $(F=11.43 ; \mathrm{df}=38,347 ; P<0.0001)$, nymphal damage scores $(F=11.87$; $\mathrm{df}=38,339 ; P<0.0001)$, and for percentage nymphal survival $(F=2.57$, $\mathrm{df}=38,339$; $P<0.0001)$. Mean adult damage scores ranged from very low (1.6) to very high $(4.8$, plant death); mean nymphal damage scores from 1.6 to 5.0 (plant death). Mean percentage survival ranged from 18 to 77 . Adult damage score and percentage nymphal survival were not correlated ( $r=0.152$, ns; $(\alpha=0.05)$, suggesting independence of resistance mechanisms. Nymphal damage score and percentage survival were correlated $(r=0.552, P<0.01)$.

Concurrent testing of the same 39 genotypes for adult and for nymph attack, with rigorous selection for resistance, allowed classification of the genotypes according to different mechanisms of resistance. In Fig. 5 , genotypes occupying the lower left quadrant (the hybrids BR 93NO/1371, FM 9406/1044/025, and BRCRUC 1027-0110, and the resistant control CIAT 6294) would be selected for having a low level of adult damage combined with antibiotic resistance to nymphs. Genotypes falling in the upper left quadrant may have tolerance to adult damage but would not be selected because previous release of cultivars expressing tolerance to spittlebug has led to breakdown of resistance under high insect pressure (Lapointe et al.
$\%$ Nymphal survival

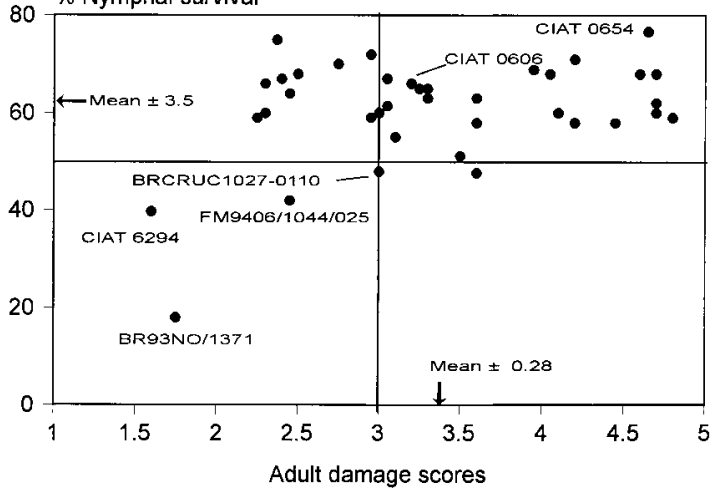

Fig. 5. Relationship between adult damage scores and percentage survival of nymphs in 39 Brachiaria spp. genotypes evaluated for resistance to the spittlebug A. varia. CIAT 6294 is the resistant control; CIAT 0606 and 0654 are susceptible controls. Solid lines mark cut-off points for resistance ( $\leq 3.0$ for visual damage scores, $\leq 50 \%$ for nymphal survival).

1992). All other genotypes (right-hand quadrants, Fig. 5) were susceptible. However, graphic representation of nymphal damage scores and percentage nymphal survival (Fig. 6) revealed that only 3 of the genotypes (lower left quadrant) were truly resistant. These are the hybrids BR93NO/1371 and BRCRUC 1027-0110 and the resistant control, CIAT 6294. The hybrid FM $9406 / 1044 / 025$ is not truly antibiotic. Its low level of nymphal survival was caused by depletion of food substrate (as reflected by the high nymphal damage score) rather than to antibiosis. Interestingly, none of the genotypes tested exhibited tolerance to nymphal attack (i.e., high survival but low nymphal damage). The other genotypes depicted in Fig. 6 were classified as susceptible.

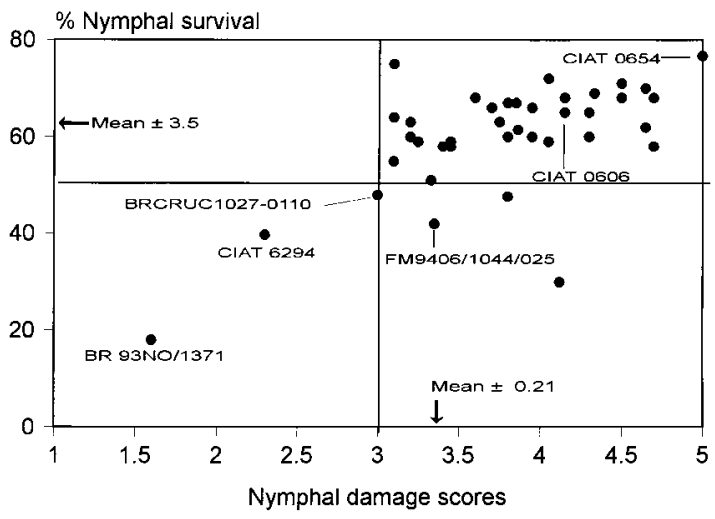

Fig. 6. Relationship between nymphal damage scores and percentage survival of nymphs in 39 Brachiaria spp. genotypes evaluated for resistance to the spittlebug A. varia. CIAT 6294 is the resistant control; CIAT 0606 and 0654 are susceptible controls. Solid lines mark cut-off points for resistance ( $\leq 3.0$ for visual damage scores, $\leq 50 \%$ for nymphal survival). 
Table 1. Resistance to $A$. varia in selected Brachiaria spp. genotypes

\begin{tabular}{lccl}
\hline \hline \multicolumn{1}{c}{ Genotype } & $\begin{array}{c}\text { Adult damage } \\
\text { scores }^{a}\end{array}$ & $\begin{array}{c}\text { Nymph damage } \\
\text { scores }^{a}\end{array}$ & $\begin{array}{c}\% \text { nymph } \\
\text { survival }\end{array}$ \\
\hline BR 93NO/1371 & $1.7 \pm 0.23 \mathrm{c}$ & $1.6 \pm 0.12 \mathrm{e}$ & $18.0 \pm 5.5 \mathrm{~d}$ \\
BRCRUC 1027-0110 & $3.0 \pm 0.48 \mathrm{~b}$ & $3.0 \pm 0.19 \mathrm{c}$ & $48.0 \pm 7.5 \mathrm{bc}$ \\
CIAT 6294 & $1.6 \pm 0.19 \mathrm{c}$ & $2.3 \pm 0.21 \mathrm{~d}$ & $39.7 \pm 6.5 \mathrm{c}$ \\
CIAT 0606 $^{c}$ & $3.2 \pm 0.30 \mathrm{~b}$ & $4.3 \pm 0.18 \mathrm{~b}$ & $65.0 \pm 7.8 \mathrm{ab}$ \\
CIAT 0654 & $4.6 \pm 0.18 \mathrm{a}$ & $5.0 \pm 0.0 \mathrm{a}$ & $76.7 \pm 5.5 \mathrm{a}$ \\
\hline
\end{tabular}

${ }^{a}$ On a $1-5$ scale ( 1 , no damage; 5 , dead plant). See text for details.

${ }^{b}$ Resistant control.

${ }^{c}$ Susceptible control.

Means \pm SEM of 10 replications per genotype. Means within a column followed by the same letter are not significantly different by LSD $(P<0.01)$

The difficulties in handling large numbers of adults, and the fact that adult damage scores can be misleading, led us to conclude that mass screening of genotypes for a plant breeding program must be conducted using infestation with nymphs. With the new screening technique it is possible to select for nymphal damage scores first, discard genotypes showing high damage scores, then count surviving nymphs (a lengthy, tedious process) only on those with low damage scores. Bioassays of selected genotypes with adults can be used later to detect tolerance, a mechanism that is a useful component of spittlebug resistance only when coupled with antibiosis (Ferrufino and Lapointe 1989, Miles et al. 1995).

Levels of resistance in selected genotypes are shown in Table 1. As compared with the susceptible controls CIAT 0606 and CIAT 0654, the hybrid BR93NO/1371 was outstanding, combining low adult damage and antibiosis to nymphs. This genotype was classified as highly resistant. In fact, it is the most resistant Brachiaria genotype tested to date for resistance to A. varia. The resistant control, CIAT 6294 (Marandú), expressed a low level of adult damage and showed low nymphal damage but was intermediate for nymphal survival. The hybrid BRCRUC 1027-0110 was classified as intermediate. Results obtained with CIAT 6294 and with the susceptible accessions CIAT 0606 and CIAT 0654 were consistent with those obtained in previous years by Ferrufino and Lapointe (1989) and Lapointe et al. (1992). Resistance ratings obtained with the new screening technique were compared with those obtained using the traditional methodology in previous years. As shown in Table 2, all genotypes found to be susceptible by the traditional methodology also were susceptible by all criteria using the new methods; of those rated resistant using the traditional screening method, 1 (BRCRUC 1016-0009) was susceptible on nymphal survival and 2 were classified as intermediate, suggesting that the new technique may be more stringent in characterizing antibiosis. BR93NO/1371 was highly resistant by all criteria. We conclude that the glasshouse screening methodology developed as a result of this work is reliable and consistent for selection of Brachiaria spp. genotypes with resistance to spittlebug.
Table 2. Comparison of resistance ratings for 39 Brachiaria genotypes tested for resistance to $A$. varia using 2 different screening methodologies

\begin{tabular}{|c|c|c|c|}
\hline \multirow{2}{*}{ Genotypes } & \multirow{2}{*}{$\begin{array}{l}\text { According to } \\
\text { traditional screening } \\
\text { methodology }{ }^{a}\end{array}$} & \multicolumn{2}{|c|}{$\begin{array}{l}\text { According to improved } \\
\text { screening methodology }\end{array}$} \\
\hline & & $\begin{array}{c}\text { Nymph } \\
\text { damage scores }\end{array}$ & $\begin{array}{c}\text { \% nymph } \\
\text { survival }\end{array}$ \\
\hline BR93NO/1371 & $\mathrm{R}$ & $\mathrm{R}$ & $\mathrm{R}$ \\
\hline CIAT $6294^{b}$ & $\mathrm{R}$ & $\mathrm{R}$ & $\mathrm{I}$ \\
\hline BRCRUC 1027-0110 & $\mathrm{R}$ & $\mathrm{R}$ & I \\
\hline BRCRUC 1016-0009 & $\mathrm{R}$ & I & $\mathrm{S}$ \\
\hline Four hybrids & I & $\mathrm{S}$ & $\mathrm{S}$ \\
\hline 29 hybrids & $\mathrm{S}$ & $\mathrm{S}$ & $\mathrm{S}$ \\
\hline CIAT $0606^{\mathrm{c}}$ & $\mathrm{S}$ & $\mathrm{S}$ & $\mathrm{S}$ \\
\hline CIAT $0654^{c}$ & $\mathrm{~S}$ & $\mathrm{~S}$ & $\mathrm{~S}$ \\
\hline
\end{tabular}

${ }^{a}$ Based on percentage nymph survival (Ferrufino and Lapointe 1989, Lapointe et al. 1992). R, resistant; I, intermediate; S, susceptible.

${ }^{b}$ Resistant control.

${ }^{c}$ Susceptible control.

The new methodology for assessment of reaction to spittlebug represents a major advance in the development of resistant Brachiaria cultivars, whether from germplasm accessions or, particularly, in plant breeding programs. The capacity of the new methodology, as measured by genotypes evaluated per unit time, is at least an order of magnitude greater than the former methods, owing to a combination of lower requirements for inputs of materials, labor, and time $(70 \%$ less space, $70-80 \%$ fewer resources, $50 \%$ less time). Improved precision means that fewer replications are required, increasing even more the throughput capacity. Although the former methods were adequate and extremely useful in screening a finite collection of germplasm accessions to identify useful sources of resistance, the massive generation of genetic recombinants from the breeding program and time constraints in advancing breeding cycles meant that early generations following initial cycles of hybridization at CIAT were advanced largely in the absence of reliable information on spittlebug reaction.

The two-year breeding cycle in CIAT's Brachiaria improvement program is now as follows. Several thousand individual progeny seedlings are produced from open pollination of selected parentals from the previous generation. These are propagated and transplanted to field trials. During the 1st year, $\approx 80 \%$ of clones are culled on visual assessment in field trials to leave $\approx 500-1000$ genotypes. Early in the 2 nd year, these clones are tested in 2 stages for spittlebug resistance with artificial infestation in the glasshouse. First, culling is on nymphal damage, using only 2 replications. The best genotypes (on the order of 100), are then rigorously retested using 10 replicates. Nymphal survival as well as damage are assessed to detect cases of mere tolerance. The 2-stage evaluation of spittlebug resistance can be completed in $4 \mathrm{mo}$. On the order of 20-50 genotypes selected for spittlebug resistance (and for 2nd-season field performance) serve as parentals for the subsequent breeding cycle. These are then recombined by open pollination of pot-grown plants during the 2 nd half of year 2 to complete the cycle. 
Although the new methodology is a major advance, still greater capacity would be desirable. Ideally, all of the several thousand open-pollinated progenies produced in each breeding cycle by recombination among parental selections would be evaluated under controlled conditions and with artificial infestation. A major breakthrough along these lines likely will not come until we have developed methodology to achieve reliable infestation of plants in large field trials. This methodology has so far proved elusive because of the multitude of uncontrollable factors operating in the field. Research is in progress to develop methods to deliver the insect to plants in the field under conditions that ensure that effective infestation is consistently achieved.

\section{References Cited}

Byers, R. A., and H. D. Wells. 1966. Phytotoxemia of coastal bermudagrass caused by two-lined spittlebug Prosapia bicincta (Homoptera: Cercopidae). Ann. Entomol. Soc. Am. 59: 1067-1071.

do Valle, C. B., and Y. H. Savidan. 1996. Genetics, cytogenetics, and reproductive biology of Brachiaria, pp. 147163. In J. W. Miles, B. L. Maass, and C. B. do Valle [eds.], Brachiaria: biology, agronomy and improvement. Centro Internacional de Agricultura Tropical, CIAT, Cali, Colombia.

Ferrufino, A., and S. L. Lapointe. 1989. Host plant resistance in Brachiaria grasses to the spittlebug Zulia colombiana. Entomol. Exp. Appl. 51: 155-162.

Hewitt, G. B. 1989. Effects of spittlebug feeding on forage and root production of Brachiaria brizantha cv. Marandú (BRA-00019). Pesqui Agropecu. Bras. 24: 307-314.

Keller-Grein, G., B. L. Maass, and J. Hanson. 1996. Natural variation in Brachiaria and existing germplasm collections, pp. 16-42. In J. W. Miles, B. L. Maass, and C. B. do Valle [ eds.], Brachiaria: biology, agronomy and improvement. Centro Internacional de Agricultura Tropical, CIAT, Cali, Colombia.

Lapointe, S. L., and J. W. Miles. 1992. Germplasm case study: Brachiaria species, pp. 43-55. In Pastures for the tropical lowlands: CIAT's contribution. Centro Internacional de Agricultura Tropical, Cali, Colombia.
Lapointe, S. L., G. Sotelo, and G. Arango. 1989a. A methodology for evaluation of host plant resistance in Brachiaria to spittlebug species (Homoptera: Cercopidae), pp. 731-732. In Proceedings, XVI International Grassland Congress, October 1989, Nice, France. INRA, Versailles, France.

1989b. Improved rearing technique for spittlebugs (Homoptera: Cercopidae). J. Econ. Entomol. 82: 1764-1766.

Lapointe, S. L., M. S. Serrano, G. L. Arango, G. Sotelo and F. Córdoba. 1992. Antibiosis to spittlebugs (Homoptera: Cercopidae) in accessions of Brachiaria spp. J. Econ. Entomol. 85: 1485-1490.

Miles, J. W., and C. B. do Valle. 1996. Manipulation of apomixis in Brachiaria breeding, pp. 164-177. In J. W. Miles, B. L. Maass, and C. B. do Valle[ eds.], Brachiaria: biology, agronomy and improvement. Centro Internacional de Agricultura Tropical, CIAT, Cali, Colombia.

Miles, J. W., S. L. Lapointe, M. L. Escandón, and G. Sotelo. 1995. Inheritance of resistance to spittlebug (Homoptera: Cercopidae) in interspecific Brachiaria spp. hybrids. J. Econ. Entomol. 88: 1477-1481.

Nilakhe, S. S. 1987. Evaluation of grasses for resistance to spittlebugs. Pesqui Agropecu. Bras. 22: 767-783.

SAS Institute. 1988. SAS/STAT user's guide, release 6.03 ed. SAS Institute, Cary, NC.

Swenne, A., B. P. Louant, and M. Dujardin. 1981. Induction par la colchicine de formes autotétraploids chez $\mathrm{Bra}$ chiaria (Graminée). Agron. Trop. 36: 134-141.

Valério, J. R., and O. Nakano. 1992. Sintomatología dos danos causados pelo adulto da cigarrinha Zulia entreriana (Berg, 1879) (Homoptera: Cercopidae) em Brachiaria decumbens Stapf. Ann. Soc. Entomol. Bras. 21: 95-100.

Valério, J. R., S. L. Lapointe, S. Kelemu, C. D. Fernandes, and F. J. Morales. 1996. Pests and diseases of Brachiaria species, pp. 87-105. In:J. W. Miles, B. L. Maass, and C. B. do Valle[eds,], Brachiaria: biology, agronomy and improvement. Centro Internacional de Agricultura Tropical, CIAT, Cali, Colombia.

Received for publication 20 July 1998; accepted 4 December 1998.

Reprinted with permission from the Entomological Society of America. Originally published in Journal of Economic Entomology 92(2):490-502, Copyright 1999. 